\title{
Back Pain in Adolescent Athletes: Results of a Biomechanical Screening
}

(-)(0) $\circledast_{\text {version } 1}$

\author{
Authors \\ Steffen Mueller ${ }^{1}$, Juliane Mueller ${ }^{1}$, Josefine Stoll ${ }^{1}$, Michael Cassel ${ }^{1}$, \\ Anja Hirschmüller ${ }^{2}$, Frank Mayer ${ }^{1}$ \\ Affiliations \\ 1 Sports Medicine \& Sports Orthopaedics, University Outpatient \\ Clinic, University of Potsdam, Potsdam, Germany \\ 2 Rehabilitative and Preventive Sports Medicine, Medical Clinic, \\ University Hospital Freiburg, Freiburg, Germany
}

Key words

trunk strength, postural control, performance, training, core stability

received $\quad 19.08 .2016$

revised 27.10 .2016

accepted 02.11 .2016

Bibliography

DOI http://dx.doi.org/10.1055/s-0042-122713

Published online: 2017 | Sports Medicine International Open

2017; 1: E16-E22

(c) Georg Thieme Verlag KG Stuttgart · New York

ISSN 2367-1890

Correspondence

Dr. Steffen Mueller

Sports Medicine \& Sports Orthopaedics

University Outpatient Clinic,

University of Potsdam

\author{
Am Neuen Palais 10 \\ 14469, Potsdam \\ Germany \\ Tel.: +49/331/977 1161, Fax: +49/331/977 1265 \\ stefmue@uni-potsdam.de
}

\begin{abstract}
The aim was to use a short biomechanical test battery to screen adolescent athletes with and without back pain to reveal relevant and possibly preventable deficits. 1559 adolescent athletes (m/f 945/614; $13.2 \pm 1.6 y$ ) were included. Back pain was assessed (1-5: 1 = no pain; $5=$ maximum pain) for dichotomous categorization into back pain (BP: pain $>2, n=113)$, healthy $\left(N_{B P}\right.$ All pain $\left.=1, n=1213\right)$ and matched healthy $\left(\mathrm{NBP}_{\text {matched }}\right.$ : pain $\left.=1, n=113\right)$ athletes. Athletes performed stability, performance (jumps) and trunk strength testing. The center of pressure displacement [mm], jump height [cm], peak force [N], contact time [ms] and peak torque of the trunk [Nm] were analyzed. Analysis showed a statistically significant influence of trunk strength on back pain $\left(\mathrm{BP} / \mathrm{NBP}_{\mathrm{ALL}}\right)$. Nevertheless, after including co-variables (anthropometrics, gender and training volume), there were no significant variables detectable any longer. ANOVA identified no group differences (BP/ $\left.\mathrm{NBP}_{\text {matched }}\right)$ in the outcome measurement for the biomechanical tests $(p>0.05)$. This short biomechanical screening shows no sufficient differentiation in adolescent athletes for back pain. Therefore, age, training load and gender has greater relevance than strength deficits or postural control. This is challenging for further understanding of the complex conditions in young athletes with back pain.
\end{abstract}

\section{Introduction}

Valid and precise risk-factor screening is essential for sports injury prevention and rehabilitation [2]. Within the spectrum of injuries, the trunk, and especially the back, is a common site of pain and dysfunction already prevalent in adolescent athletes [27,36]. Depending on the definition of back pain location (e. g., back, low back, upper back), time window (e. g., point, 3-month or lifetime prevalence) and investigated population (age, training volume), the reported prevalence differs considerably. However, the point prevalence of back pain is rather low in young athletes under 13 years of age ( $<10 \%)$. Nevertheless, at the age of 14 , back pain prevalence in athletes is dramatically increased ( $>20 \%)[27,36]$. For 3-6 month back pain prevalence, even higher numbers (>30\%) are shown for adolescent athletes [21, 29, 32]. For most of the cases, a structural correlate to back pain is still lacking, and therefore only non-specific back pain is diagnosed [39]. Even if well-defined risk factors are not evident, differences in function between healthy controls and back pain patients are known for adults [24, 28, 31].
As reported in numerous studies, different types of sports reveal specific demands on neuromuscular function [4, 28]. Nevertheless, Kibler et al. described the role and importance of core stability for all types of sports, whether running, throwing or jumping tasks [19]. High impact forces on the trunk are reported in gymnastics, rhythmic gymnastics, judo, weight lifting, rowing and jumping [16, 22, 30]. Repetitive loading with significant components of translation, rotation and reclination are believed to result in high impact forces $[1,18]$. Therefore, it is proposed that athletes need a highly developed functional trunk capacity in order to compensate these sport-specific loads. If this ability is inadequate, athletes with high demands on trunk strength and stability will have a greater risk of sustaining an injury or developing back pain $[1,41]$. This supports the recent theoretical approach of discussing reduced function and trunk stability not only as a result but also as a risk factor for back pain.

Reduced trunk extension strength has been shown in both untrained adults and adult athletes with back pain [28, 34]. Trunk strength capacity is therefore considered to be an essential mark- 
er compensating external forces and loads [19,41]. In addition, trunk strength may directly or indirectly influence athletic performance in competition $[7,16,19]$. Thus, muscle strength can be seen as a relevant factor in preventing sports-related injuries in young athletes [7, 19]. Furthermore, Zazulak et al. showed an association between reduced core stability, reduced muscular trunk strength and a higher injury risk at the lower extremities in young (female) athletes [41]. Differences in trunk strength capacity depending on gender, age and sport type have been identified in healthy adults as well as adolescent athletes $[13,26,28,37]$. Therefore it might not be valid to transfer results from untrained adults or adult athletes to adolescent athletes.

In addition, both postural control and complex neuromuscular control of movements are discussed as determinants used to quantify functional deficits in back pain $[8,33]$. Associations between postural control and training experience are only evident in untrained adolescents. Biec and Kuczyński [6] showed improved postural control due to systematic training even in 13-year-old soccer players compared to non-athletes. Recent studies support the hypothesis that adults suffering from low back pain show reduced postural control $[8,33]$. Nevertheless, it is unclear whether these results regarding prevention and rehabilitation are transferable to adolescent athletes. Further, pre-participation examinations in young athletes are frequently applied to evaluate eligibility for competitive sports, giving possibilities for additional functional screening to identify potential risk factors for back pain [23]. Screening tools should be capable of clearly detecting deficits between healthy and injured athletes. It has been hypothesized that reduced trunk strength, postural control and/or neuromuscular control, e. g., in complex movement tasks, negatively influences function and trunk stability, which results in an increased risk of back pain occurrence, recurrence or pain chronification [7]. Since this paradigm is getting increasing approval and exercise is one of the most evident treatments to prevent back pain reoccurrence or to reduce (acute/chronic) back pain, a valid short test battery to identify functional deficits is desired $[7,10,15,35]$. A targeted allocation to specific exercise interventions enhancing these deficient factors is lacking but could possibly be derived from valid diagnostics to better prevent and treat back pain in athletes. Therefore, the test battery should involve postural control, strength capacity and complex high-intensity tasks to represent functional deficits.

Therefore, this study aims to investigate a short biomechanical test battery to screen adolescent athletes both with and without back pain in order to determine deficits valid to serve as risk factors for prevention strategies. Our hypothesis would lead to the expectation of reduced function, measurable by reduced postural control, jump performance and trunk strength in athletes with back pain.

\section{Material and Methods Subjects}

2389 adolescent athletes between 11 and 17 years of the elite schools of sports of the federal state of Brandenburg (inclusion criteria), Germany, were enrolled in the study. Athletes with contraindications for exercise, stance, jump or maximum trunk strength test and athletes with intake of pain medication were excluded by medical investigation. Due to incomplete datasets, $\mathrm{N}=830$ athletes had to be excluded for further analysis, resulting in $\mathrm{N}=1559$ athletes (m/f 945/614; $13.2 \pm 1.6 ; 163.2 \pm 11.5 \mathrm{~cm} ; 52.6 \pm 13.7 \mathrm{~kg}$; $8.4 \pm 5.8$ training $\mathrm{h} /$ week) for complete case analysis (Analysis I, Ila). The athletes come from 19 different sport types (artistic gymnastic $(n=19)$, boxing $(n=45)$, canoeing $(n=75)$, cycling $(n=113)$, finswimming $(n=6)$, handball $(n=196)$, horse riding $(n=70)$, judo $(n=109)$, karate $(n=4)$, pentathlon $(n=32)$, rowing $(n=100)$, shooting ( $n=34)$, soccer $(n=202)$, swimming $(n=80)$, track and field $(n=210)$, triathlon $(n=11)$, volleyball $(n=56)$, weight lifting $(n=42)$, wrestling $(n=134)$, not defined $(n=21))$. Additionally, a subgroup analysis of all back pain athletes (BP; $n=113$ ) with 113 age- and gender-matched "no back pain" athletes (NBP matched) was conducted (Analysis IIb).

All participants and their legal guardians were informed of the study and the specific testing procedures in a personal conversation with the principal investigator and through written study information during their stay at the university outpatient clinic. Before voluntary participation in the study, the legal guardians and children provided written informed consent. The University Ethical Committee approved all procedures conducted during the study [14].

\section{Procedures}

A cross-sectional study design was used to evaluate postural control (one-legged stance), jump performance and maximal trunk strength capacity in young athletes with and without back pain. All test situations were implemented as a biomechanical screening tool in the annual (pre-participation) examination of incoming and current students in elite sports schools [23, 26].

The test protocol started with a medical check-up to ensure that all participants were suitable for the upcoming biomechanical testing. In addition, anthropometric data and training history were assessed. Furthermore, subjective back pain was assessed using a standardized (face scale) questionnaire [25, 27]. Following this, all athletes underwent a general physical warm-up of at least 5 min prior to testing. The functional biomechanical screening tool included 3 tests. First, postural control (PC) was assessed during one-legged stance (barefoot, hands to the hip, view straight forward). After demonstration and one practice trial, 3 repetitions for left and right leg (randomized order) were performed for $10 \mathrm{~s}$ on a force plate (Amti OR6-6, Advanced Mechanical Technology, Inc., Watertown, MA, USA.) with $15 \mathrm{~s}$ rest between repetitions. The athletes had to keep their stance as stable and balanced as possible.

Second, complex motor performance was assessed via countermovement jumps (CMJ) and drop jumps (DJ). Initial instruction was followed by a demonstration and one practice trial before the jump measurements were performed. Always 3 repetitions were captured for CM] and DJ with a ground reaction force plate (Amti OR6-6, Advanced Mechanical Technology, Inc., Watertown, MA, USA). DJ was performed from a box $20 \mathrm{~cm}$ in height. The rest period was set at $15 \mathrm{~s}$ between the 3 repetitions for each jump and 2 min between the 2 different jumps.

Third, maximum trunk strength capacity was assessed. The trunk strength measurement (TS) protocol began with a 90-s local warm-up and familiarization trial (isokinetic trunk flexion/extension), identical to the maximum test and performed at a moderate intensity. After a 60 -s rest period, maximum isokinetic strength was tested concentrically at $60 \%$ with 5 repetitions and a range of 
motion (ROM) of $55^{\circ}\left(10^{\circ}\right.$ extension to $45^{\circ}$ flexion; CON-TREX M] TP 1000 ; Physiomed Elektromedizin AG, Germany). Additional information for this standardized trunk testing protocol are detailed in a previous study [26] ( $\triangleright$ Fig. 1).

\section{Outcome measurements and data analysis}

Subjective back pain was assessed using a standardized questionnaire consisting of a 5-step graded faces pain scale (FPS: face $1=$ no pain; face 2 = little pain; face 3 = moderate pain; face 4 = strong pain; face 5 = maximum imaginable pain) $[25,27]$. This type of questionnaire is considered valid for the use of subjective pain assessment in children and adolescents [20,25].

The main outcome measurements analyzed for $P C$ testing were the displacement [mm] of the centre of pressure (COP) in the anterior-posterior (a-p) and medio-lateral ( $\mathrm{m}-\mathrm{l})$ directions, as well as the overall COP displacement (o) for the 10-s time interval analyzed (best trial (minimum) out of all left and right trials). For the jumps (CMJ/DJ), jumping height (Height $\mathrm{CMJ} / \mathrm{D}]_{\text {; }}$ computed from flight time using the formula: $1 / 8^{*} \mathrm{~g}\left[\mathrm{~m} / \mathrm{s}^{2}\right]$ * time $[\mathrm{s}]^{2}$; [cm]), maximum peak force at take-off $\left(\mathrm{Fz}_{\mathrm{CM} / \mathrm{DD}} ;[\mathrm{N}]\right)$ and ground contact time (Contact ${ }_{D]}$; [ms]) were calculated as the mean of 3 repetitions. Regarding trunk strength testing, absolute peak torque [ $\mathrm{Nm}]$ in flexion $\left(\right.$ Flex $\left._{\mathrm{abs}}\right)$ and extension $\left(\mathrm{Ext}_{\mathrm{abs}}\right)$ served as the main outcome measurements and were calculated as the mean of the 3 highest torque values from 5 repetitions $[4,26]$.

\section{Statistical analysis}

All non-digital data were documented in a handwritten case report form (CRF) and transferred to a database (JMP Statistical Software Package 8 , SAS Institute ${ }^{\circledR}$ ). All data ranges were checked for plausibility (e. g.: age: $11-18$ years; body size: $1.40 \mathrm{~m}>\mathrm{x}<2.00 \mathrm{~m}$; body mass: $<120 \mathrm{~kg}$; peak torque: $<400 \mathrm{Nm}$ ). Implausible data and extreme values were recalculated or revised.

Statistical analysis was done descriptively (frequency; mean \pm standard deviation (SD); $95 \%$ confidence interval $\mathrm{Cl}$ ) for all measurements, followed by multiple logistic regression and ANOVA ( $\alpha=0.05$, post hoc Tukey-Kramer) including calculation of effect size (G * Power 3.1.9.2; [d]). First, the multiple logistic regression was applied for the complete case data set (independent variable: biomechanical screening measurements; co-variables: anthropometric variables and training volume; dependent variable: back pain FPS). Second, in accordance with the FPS, athletes were classified as athletes with or without back pain: group "No Back Pain (All)" (NBP All; FPS $=1 \mathrm{n}=1213)$ and group "Back Pain" (BP; FPS $>2$ $n=113$ ). All athletes reporting pain on FPS $=2$ (little pain: defined as no relevant pain) were excluded for this dichotomous group analysis [25]. Furthermore, a subgroup analysis of the $n=113$ back pain athletes (BP) with $n=113$ age- and gender-matched controls (NBPmatched) was conducted to account for the known anthropometric confounders [9, 26] ( Fig. 2). Anthropometric and training characteristics for matched groups (BP/NBP matched $)$ are detailed in - Table 1. One-way ANOVA $(\alpha<0.05)$ was used to analyze differences for $\mathrm{BP}$ and $\mathrm{NBP}_{\mathrm{All}} / \mathrm{NBP}_{\text {matched}}$.

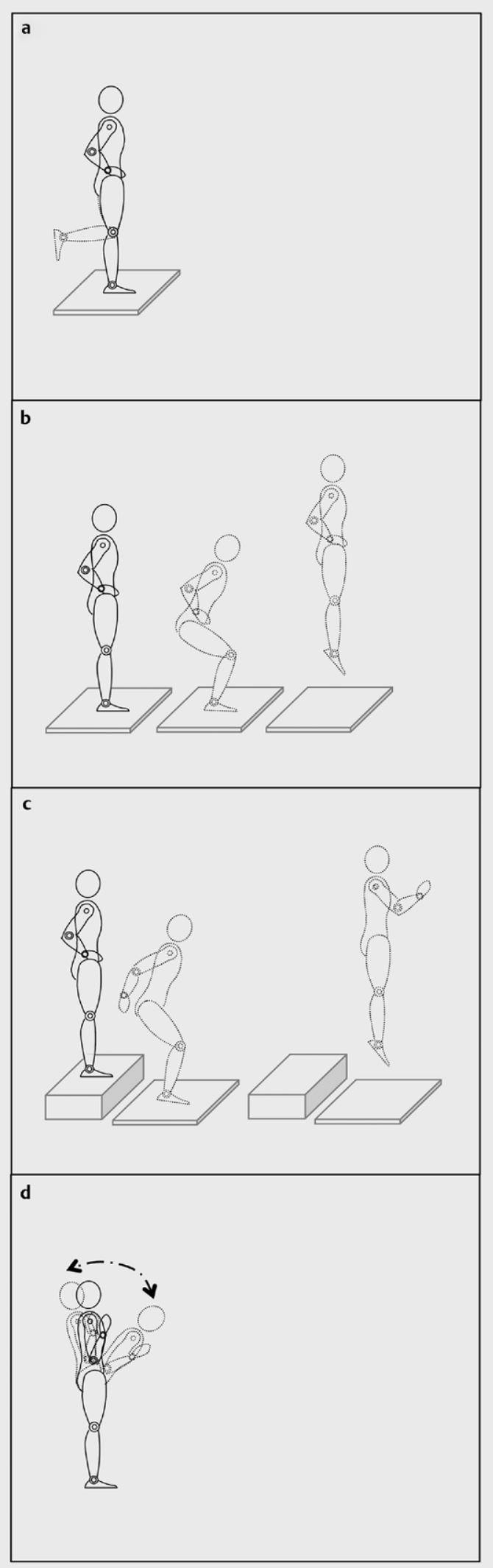

- Fig. 1 Functional biomechanical screening tests: a one-legged stance, $\mathbf{b}$ countermovement jump, $\mathbf{c}$, drop jump and $\mathbf{d}$ maximum (isokinetic) trunk strength testing in extension/flexion. 


\section{Results}

\section{Complete case analysis}

The pain questionnaire analysis revealed that $78 \%$ of the athletes reported no pain (face $1 ; \mathrm{N}=1213$ ), $15 \%$ little (face $2 ; \mathrm{N}=233$ ), $5 \%$ moderate (face 3; $\mathrm{N}=85$ ), $1 \%$ strong (face $4 ; \mathrm{N}=22$ ) and less than $1 \%$ maximum pain (face $5 ; \mathrm{N}=6$ ).

Regression analysis for the biomechanical variables showed a statistically significant influence of maximal trunk extension (Ext $\mathrm{abs}_{\text {; }}$; $\left.\mathrm{Chi}^{2}=0.0085\right)$ and flexion strength (Flex abs; $\left.\mathrm{Chi}^{2}=0.0015\right)$ on back pain (generalized $r^{2}=0.11$ ). No influence was shown for all other biomechanical variables. After including the co-variables (age, training volume, gender, body height and mass) into the model, no biomechanical screening outcome measurement presented any more influence on back pain. In contrast, age $\left(\mathrm{Chi}^{2}<0.0001\right)$, training volume $\left(\mathrm{Chi}^{2}=0.0028\right)$ and gender $\left(\mathrm{Chi}^{2}=0.0376\right)$ presented an influence on back pain (generalized $r^{2}=0.17$ ).

\section{$\mathrm{BP}$ and $\mathrm{NBP}_{\mathrm{ALL}}$ group analysis}

Anthropometric and training data of $\mathrm{BP}$ and $\mathrm{NBP}_{\mathrm{All}}$ showed that athletes without back pain were significantly younger, smaller and lighter. They also boasted fewer training years and training hours per week ( Table 2A). Additionally, analysis of the biomechanical screening tool resulted in differences between $\mathrm{BP}$ and $\mathrm{NBP}_{\mathrm{All}}$ for jumping

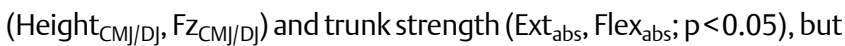
not for the one-legged stance ( $p>0.05$; > Fig. 2, 3, 4; $>$ Table 1).

\section{$\mathrm{BP}$ and $\mathrm{NBP}_{\text {matched }}$ group analysis}

The matched-group analysis did not reveal any differences for anthropometric or training data between the groups BP and $\mathrm{NBP}_{\text {matched }}(\triangleright$ Table $2 \mathrm{~B})$.

Overall, the COP displacement (postural control: PC) did not dif-

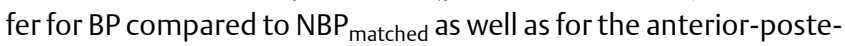
rior and medio-lateral directions ( $>$ Fig. 2; $p>0.05$ ).

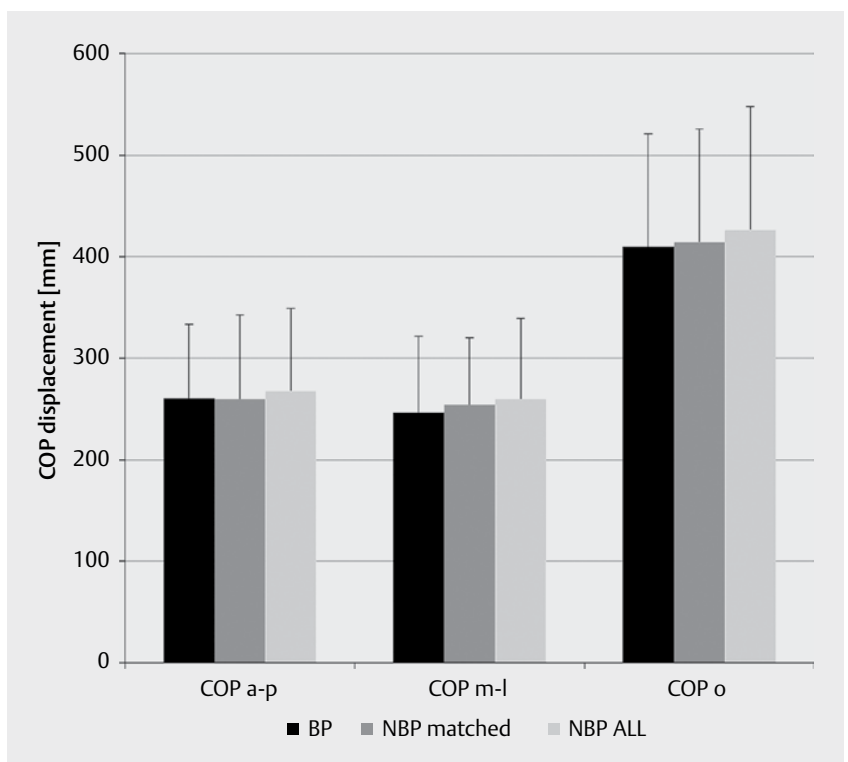

- Fig. 2 COP displacement for anterior-posterior $\left(\mathrm{COP}_{\mathrm{a}-\mathrm{p}}\right)$, medio-lateral directions $\left(\mathrm{COP}_{\mathrm{m}-1}\right)$ and overall distance $\left(\mathrm{COP}_{\mathrm{o}}\right)[\mathrm{mm}]$ for 10-s one-legged stance for athletes with (BP) and without $\left(\mathrm{NBP}_{\text {matched }} / \mathrm{NBP}_{\text {All }}\right)$ back pain (mean $\left.\pm \mathrm{SD}\right)$
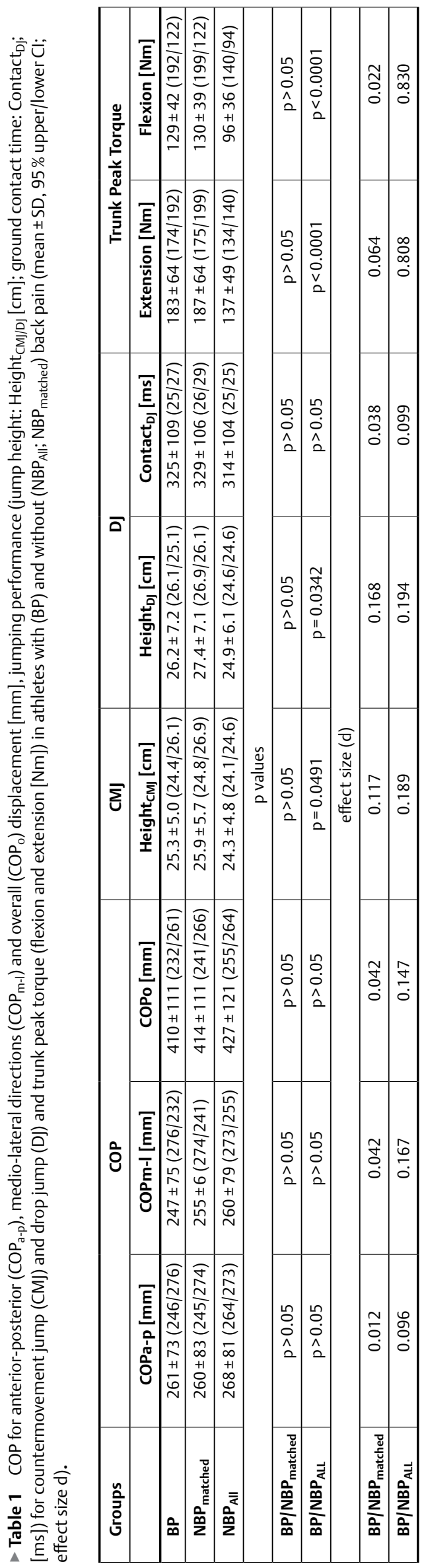
- Table 2 Characteristics of adolescent athletes (anthropometric, back pain and training data) with (BP) and without back pain ( $\mathrm{NBP}_{\mathrm{AL}}$; $\left.\mathrm{NBP}_{\text {matched }}\right)$.

\begin{tabular}{|c|c|c|c|c|c|c|}
\hline \multicolumn{7}{|c|}{ A) Back pain category for all athletes } \\
\hline Group & Pain scale (FPS) & Gender $[\mathbf{m} / \mathbf{f}]$ & Age [years] & Height $[\mathrm{cm}]$ & Weight [kg] & Training [h/week] \\
\hline \multirow[t]{2}{*}{$\mathrm{NBP}_{\text {All }}$} & 1 (no pain) & $741 / 472$ & $12.9 \pm 1.5$ & $161.8 \pm 11.1$ & $50.8 \pm 13.1$ & $7.5 \pm 5.2$ \\
\hline & 2 & $139 / 94$ & $14.0 \pm 1.8$ & $166.8 \pm 11.9$ & $57.0 \pm 13.9$ & $10.5 \pm 6.6$ \\
\hline \multirow{3}{*}{ BP } & 3 & $50 / 35$ & $14.6 \pm 1.5$ & $170.5 \pm 11.3$ & $61.5 \pm 12.7$ & $13.0 \pm 6.2$ \\
\hline & 4 & $13 / 9$ & $15.3 \pm 0.6$ & $172.7 \pm 9.2$ & $66.1 \pm 12.6$ & $14.0 \pm 4.9$ \\
\hline & 5 (max pain) & $2 / 4$ & $14.8 \pm 1.5$ & $166.5 \pm 14.9$ & $63.0 \pm 16.3$ & $14.8 \pm 5.4$ \\
\hline \multicolumn{7}{|c|}{ B) Athletes with (BP) and matched athletes without $\left(\mathrm{NBP}_{\text {matched }}\right)$ back pain } \\
\hline BP & $3-5$ & $65 / 48$ & $14.7 \pm 1.4$ & $170.7 \pm 11.1$ & $62.5 \pm 12.9$ & $13.3 \pm 5.9$ \\
\hline $\mathrm{NBP}_{\text {matched }}$ & 1 & $65 / 48$ & $14.7 \pm 1.4$ & $170.6 \pm 10.1$ & $60.7 \pm 11.4$ & $12.8 \pm 6.1$ \\
\hline
\end{tabular}

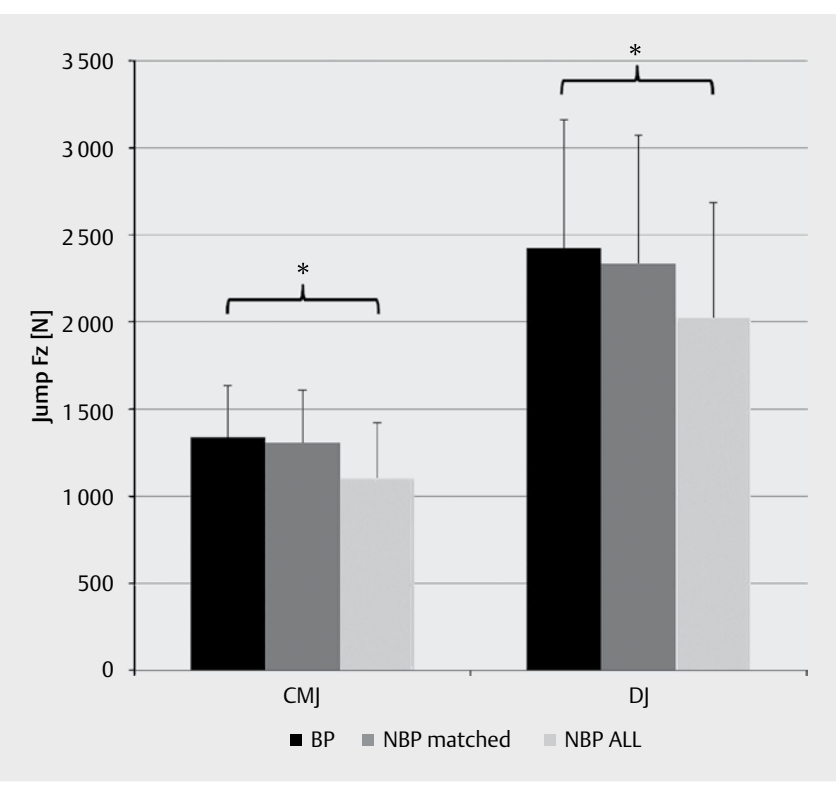

Fig. 3 Maximum peak force at take-off Fz [N] for countermovement jump (CMJ) and drop jump (DJ) for athletes with (BP) and without $\left(\mathrm{NBP}_{\text {matched }} / \mathrm{NBP}_{\text {All }}\right)$ back pain $($ mean $\pm \mathrm{SD})\left({ }^{*} \mathrm{p}<0.05\right)$.

All variables analyzed for the countermovement jump (CMJ) and drop jump (DJ) ( $\mathrm{Fz}_{\mathrm{CM}}$, Height $\mathrm{CM}_{\mathrm{CM}}, \mathrm{Fz}_{\mathrm{D} J}$, Contact $\mathrm{D}_{\mathrm{D}}$, Height $\left.\mathrm{DJ}_{\mathrm{DJ}}\right)$ did not show differences between $\mathrm{NBP}_{\text {matched }}$ and $\mathrm{BP}(\triangleright$ Table 1, $\triangleright$ Fig. 3; $\mathrm{p}>0.05$ ).

Absolute peak torque in trunk flexion was $129.5 \pm 39.0 \mathrm{Nm}$ in the $\mathrm{NBP}_{\text {matched }}$ group and $128.6 \pm 42.4 \mathrm{Nm}$ in the BP group. For trunk extension, the peak torque was $187.0 \pm 63.3 \mathrm{Nm} / 182.9 \pm 63.8 \mathrm{Nm}$ in the $\mathrm{NBP}_{\text {matched }} / \mathrm{BP}$ group. There are no statistically significant differences between BP and NBP matched $(p>0.05)$ in terms of absolute peak torque, in either flexion or extension ( $\mathbf{F i g} .4$ ).

\section{Discussion}

The purpose of this study was to evaluate whether a short biomechanical test battery could be used to identify the relevant variables influencing the presence of back pain and to differentiate between adolescent athletes with and without back pain. As a result, it could be shown that this functional biomechanical screening tool including postural control, trunk strength and jump

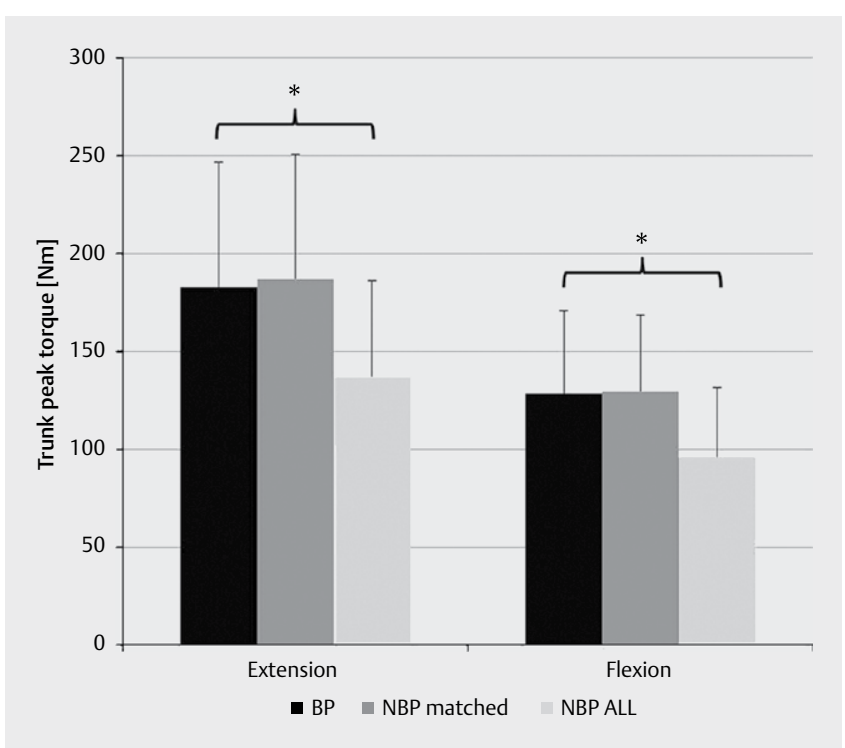

- Fig. 4 Flexion and extension trunk peak torque $[\mathrm{Nm}]$ for athletes with $(\mathrm{BP})$ and without $\left(\mathrm{NBP}_{\text {matched }} / \mathrm{NBP}_{\text {All }}\right)$ back pain $\left({ }^{*} \mathrm{p}<0.05\right)$.

performance testing does not differentiate between adolescent athletes with and without back pain.

Nevertheless, age and training volume could be shown as the main influencing factors and this is in line with the back pain prevalence in adolescent athletes [27,36]. Athletes with back pain tend to be older and exposed to a higher training volume [27]. Similar findings are found for the overall injury rate of athletes between 7 to 18 years of age in a recent study by Jayanthi et al. [17]. This also leads to the hypothesis that the relationship of injury prevalence and training volume is $\mathrm{U}$-shaped, meaning an excessive training load might affect injury risk. Nevertheless, it is unclear whether age or training volume itself leads to higher prevalence because the 2 factors coexist in the normal development of the athletes' training, and prospective studies are lacking [17].

Furthermore, the adolescent athletes showed an expected increase in trunk strength capacity, postural control, and jump performance along with increasing age and training volume independent of subjective back pain [26]. To account for this, a matchedgroup analysis was applied, diminishing any significant differences in the functional biomechanical testing. Therefore, previously reported and evident functional deficits, e. g., reduced postural con- 
trol and reduced trunk extensor strength in adults with back pain are not transferable to highly trained adolescent athletes with back pain $[8,28,34]$. The investigation by Noll et al. could be relevant in this context [29]. Noll et al. found differences for trunk strength capacity that we did not find using the biomechanical test battery for our athletes with and without back pain [29]. One reason for these contradictory findings could be seen in the different characteristics of the investigated participants. Our athletes were more than 3 years younger and had an extremely higher training volume. Furthermore, the duration of back pain is not equal in the studies and could additionally influence the results. Especially highly trained (elite) athletes ( $\approx 13 \mathrm{~h} /$ week) with back pain may evidence fewer effects in biomechanical variables compared with low or moderately trained athletes (1-6 training sessions/week) [29].

Potentially, the equivalent training volume for $\mathrm{BP}$ and $\mathrm{NBP}_{\text {matched }}$ athletes could be discussed as one possible reason for the lack of functional deficits.

Therefore, disuse and deconditioning often seen in adults with (chronic) low back pain is probably not present in adolescent athletes $[3,40]$.

Current literature discusses increased age and training load as risk factors for back pain in adolescent athletes, often assessed with self-reported standardized questionnaires [5, 27, 36]. These factors correspond to the findings presented here, namely that anthropometrics and training volume are the main factors that differentiate between $\mathrm{BP}$ and $\mathrm{NBP}_{\text {All }} / \mathrm{NBP}_{\text {matched }}$. These findings are supported by Trainor \& Wiesel [38], who reported that a sudden change in the training process, including increased volume, is a common cause of back pain. In addition, in a recent study with adolescent non-athletes, Bernard et al. [5] concluded that training volume and loading at this stage of development (adolescence) and sports career (transition to high-performance sports) should be increased with caution. Coaches, physicians and clinicians working with adolescent high-performance athletes need to consider these results in order to counteract back pain development with prevention strategies and adapted training volumes.

Differences between adults with and without back pain have been shown on a neuromuscular level. Reduced muscular reaction time of the trunk-encompassing muscles to sudden, unexpected loading is considered to be one factor eliciting low back pain $[11,31]$. Consequently, the inadequate neuromuscular compensation of sudden, repetitive loading is discussed as a risk factor for back pain development in athletes [11,31]. Therefore, a more complex biomechanical screening tool including electromyography analysis and more challenging testing situations (e.g., perturbations) might be useful to detect differences between adolescent athletes with and without back pain [11,31]. However, the feasibility and transfer of such complex biomechanical measurement tools to daily practice have to be discussed critically. In contrast, a short test-battery could possibly be implemented in preparticipation examinations and annual health checks or regular field tests conducted by coaches during training sessions. For transfer into the field, postural control and jump performance could be easily assessed by affordable and valid force sensors and (isometric) trunk strength capacity by sequence apparatus [12].

Nonetheless, certain limitations of the study have to be discussed. It must be mentioned that the athletes analyzed were re- cruited out of 19 different types of sports, presenting different demands on trunk strength capacity and stability during performance $[4,28]$. Therefore, athletes from different types of sports might have different levels of postural control, trunk strength and jump performance, but there were no differences in distribution of the athletes with and without back pain in terms of the different types of sports included in the analysis.

Moreover, pain assessment and (low) back pain classification might be discussed as an influencing factor on the results presented here and comparability with the literature. In general, the faces pain scale (FPS) questionnaire has been validated for the use of pain assessment in children and adolescents $[20,25]$ and seems to be a suitable tool for a feasible transfer into the practical field of sports (e. g., coaches) and sports medicine (e.g., physiotherapists) to identify athletes in pain.

\section{Practical implications}

A feasible short biomechanical screening tool including postural control, jump performance and trunk strength testing is not able to identify the influencing factors in back pain or to differentiate between adolescent athletes with and without back pain. Therefore, the biomechanical test battery is not valid for application. In contrast, adolescent athletes with BP are significantly older with higher body weight and size compared to healthy ones. In addition, adolescent athletes with BP have significantly more training years and training volume compared to healthy ones. Therefore, age and training volume are relevant factors at this stage of development and sports career and must be considered during the training process [2,3]. For future investigation, this implies the need for special attention to training load (volume, intensity) in combination with biomechanical characteristics. Furthermore, a neuromuscular approach using EMG analysis and perturbation tests, for example, might be beneficial. Finally, this evidence demands an adaptation of perspective warranted by the possible presence of a specific or complex condition in elite adolescent athletes with back pain.

\section{Acknowledgements}

This study was supported by a research grant from the National Institute of Sport Science of Germany (granted number: BISp IIA 1-080126/09-13).

\section{Conflict of Interest}

The authors declare that they have no conflict of interest.

\section{References}

[1] Adirim TA, Cheng TL. Overview of injuries in the young athlete. Sports Med 2003; 33: 75-81

[2] Bahr R. Understanding injury mechanisms: a key component of preventing injuries in sport. Br J Sports Med 2005; 39: 324-329

[3] Balagué F, Mannion AF, Pellisé F, Cedraschi C. Non-specific low back pain. Lancet 2012; 379: 482-491 
[4] Baur H, Müller S, Pilz F, Mayer P, Mayer F. Trunk extensor and flexor strength of long-distance race car drivers and physically active controls. J Sports Sci 2010; 28: 1183-1187

[5] Bernard JC, Boudokhane S, Pujol A, al E. Isokinetic trunk muscle performance in pre-teens and teens with and without back pain. Ann Phys Rehabil Med 2014; 57: 38-54

[6] Bieć E, Kuczyński M. Postural control in 13-year-old soccer players. Eur J Appl Physiol 2010; 110: 703-708

[7] Borghuis J, Hof AL, Lemmink KAPM. The importance of sensory-moto control in providing core stability: implications for measurement and training. Sports Med 2008; 38: 893-916

[8] Caffaro RR, França FJR, Burke TN, Magalhães MO, Ramos LAV, Marques AP. Postural control in individuals with and without non-specific chronic low back pain: a preliminary case-control study. Eur Spine ] 2014; 23: 807-813

[9] Cavalheiro GL, Almeida M, Pereira AA, Andrade AO. Study of age-related changes in postural control during quiet standing through Linear Discriminant Analysis. BioMed Eng OnLine 2009; 8: 35

[10] Choi BK, Verbeek JH, Tam WW-S, jiang JY. Exercises for prevention of recurrences of low-back pain. Cochrane Database Syst Rev 2010 CD006555

[11] Cholewicki J, Simons APD, Radebold A. Effects of external trunk loads on lumbar spine stability. J Biomech 2000; 33: 1377-1385

[12] Clark RA, Bryant AL, Pua Y, McCrory P, Bennell K, Hunt M. Validity and reliability of the Nintendo Wii Balance Board for assessment of standing balance. Gait Posture 2010; 31: 307-310

[13] Cowley PM, Fitzgerald S, Sottung K, al E. Age, weight, and the front abdominal power test as predictors of isokinetic trunk strength and work in young men and women. J Strength Cond Res 2009; 23 : 915-925

[14] Harriss D], Atkinson G. Ethical standards in sport and exercise science research: 2016 update. Int J Sports Med 2015; 36: 1121-1124

[15] Hayden JA, van Tulder MW, Malmivaara A, Koes BW. Exercise therapy for treatment of non-specific low back pain. Cochrane Database Syst Rev 2005; 3:CD000335

[16] Hibbs AE, Thompson KG, French D, Wrigley A, Spears I. Optimizing performance by improving core stability and core strength. Sports Med 2008; 38: 995-1008

[17] Jayanthi NA, LaBella CR, Fischer D, Pasulka J, Dugas LR. Sports-specialized intensive training and the risk of injury in young athletes: a clinical case-control study. Am J Sports Med 2015; 43: 794-801

[18] Jones MA. Biological risk indicators for recurrent non-specific low back pain in adolescents. Br J Sports Med 2005; 39: 137-140

[19] Kibler WB, Press ], Sciascia A. The role of core stability in athletic function. Sports Med 2006; 36: 189-198

[20] Kropp P. Psychologische Schmerzdiagnostik bei Kindern. Schmerz 2004; 18: 61-74

[21] Legault ÉP. Musculoskeletal symptoms in an adolescent athlete population: a comparative study. BMC Musculoskelet Disord 2015; 16 : 210

[22] Liemohn WP, Baumgartner TA, Gagnon LH. Measuring core stability. J Strength Cond Res 2005; 19: 583-586

[23] Mayer F, Bonaventura K, Cassel M, Mueller S, Weber J, Scharhag-Rosenberger F, Carlsohn A, Baur H, Scharhag J. Medical results of preparticipation examination in adolescent athletes. Br J Sports Med 2012; 46: 524-530

[24] Mazaheri M, Coenen P, Parnianpour M, Kiers H, van Dieën JH. Low back pain and postural sway during quiet standing with and without sensory manipulation: A systematic review. Gait Posture 2013; 37: $12-22$
[25] Merati G, Negrini S, Carabalona R, al E. Trunk muscular strength in pre-pubertal children with and without back pain. Pediatri Rehabil 2004; 7: 97-103

[26] Mueller J, Mueller S, Stoll J, Baur H, Mayer F. Trunk extensor and flexor strength capacity in healthy young elite athletes aged $11-15$ years. J Strength Cond Res 2014; 28: 1328-1334

[27] Müller J, Muller S, Stoll J, Fröhlich K, Otto C, Mayer F. Back pain prevalence in adolescent athletes. Scand J Med Sci Sports 2016; doi: 10.1111/sms.12664 [Epub ahead of print]

[28] Müller S, Stoll J, Müller J, Mayer F. Validity of isokinetic trunk measurements with respect to healthy adults, athletes and low back pain patients. Isokinet Exerc Sci 2012; 20: 255-266

[29] Noll M, de Avelar IS, Lehnen GC, Vieira MF. Back pain prevalence and its associated factors in Brazilian athletes from public high schools: a cross-sectional study. PLoS ONE 2016; 11: e0150542-16

[30] Peate WF, Bates G, Lunda K, Francis S, Bellamy K. Core strength: A new model for injury prediction and prevention. J Occup Med Toxicol 2007; 2: 3

[31] Radebold A, Cholewicki J, Polzhofer GK, Greene HS. Impaired postural control of the lumbar spine is associated with delayed muscle response times in patients with chronic idiopathic low back pain. Spine 2001; 26: 724-730

[32] Rossi M, Pasanen K, Kokko S, Alanko L, Heinonen OJ, Korpelainen R, Savonen K, Selanne H, Vasankari T, Kannas L, Kujala U, Villberg J, Parkkari J. Low back and neck and shoulder pain in members and non-members of adolescents' sports clubs: the Finnish Health Promoting Sports Club (FHPSC) study. BMC Musculoskelet Disord 2016; 17: 263

[33] Ruhe A, Fejer R, Walker B. Center of pressure excursion as a measure of balance performance in patients with non-specific low back pain compared to healthy controls: a systematic review of the literature. Eur Spine J 2010; 20: 358-368

[34] Saito Y, Iwai K, Nakazato K, Irie K, Mizuno M, Nakajima H. Physical characteristics of collegiate track and field athletes with low back pain. Japanese Journal of Physical Fitness and Sports Medicine 2009; 58 : 99-108

[35] Saragiotto BT, Maher CG, Yamato TP, Costa LO, Menezes Costa LC, Ostelo RW, Macedo LG. Motor control exercise for chronic non-specific low-back pain. Cochrane Database Syst Rev 2016; 1: CD012004

[36] Schmidt CP, Zwingenberger S, Walther A, Reuter U, Kasten P, Seifert J, Günther KP, Stiehler M. Prevalence of low back pain in adolescent athletes - an epidemiological investigation. Int J Sports Med 2014; 35 : 684-689

[37] Skrzek A, Ignasiak Z, Kozieł S, Sławińska T, Rożek K. Differences in muscle strength depend on age, gender and muscle functions. Isokinet Exerc Sci 2012; 20: 229-235

[38] Trainor TJ, Wiesel SW. Epidemiology of back pain in the athlete. Clin Sports Med 2002; 21: 93-103

[39] van Tulder M, Becker A, Bekkering T, Breen A, del Real MTG, Hutchinson A, Koes B, Laerum E, Malmivaara A. COST B13 Working Group on Guidelines for the Management of Acute Low Back Pain in Primary Care. Chapter 3. European guidelines for the management of acute nonspecific low back pain in primary care. Eur Spine J 2006; 15 (Suppl 2): S169-S191

[40] Verbunt JA, Seelen HA, Vlaeyen JW, van der Heijden G], Knottnerus JA. Fear of injury and physical deconditioning in patients with chronic low back pain. YAPMR 2003; 84: 1227-1232

[41] Zazulak BT, Hewett TE, Reeves NP, Goldberg B, Cholewicki J. Deficits in neuromuscular control of the trunk predict knee injury risk: a prospective biomechanical-epidemiologic study. Am J Sports Med 2007; 35: 1123-1130 